\title{
Sobre Aprender Matemática com a Arte, ou Matemática e Arte e Visualidade em Experiência na Escola
}

\section{Learning Mathematics with Art, or Mathematics and Art and Visuality in School Experience}

\author{
Cláudia Regina Flores* \\ ORCID iD 0000-0003-2351-5712 \\ Mônica Maria Kerscher** \\ ORCID iD 0000-0002-1710-1719
}

\begin{abstract}
Resumo
Este artigo problematiza o aprender Matemática pela e com a Arte. Parte-se de questionamentos, entre eles: Como não representar a Matemática na Arte, nem instrumentalizar a Educação Matemática, mas fazer disso uma experiência filosófica com Arte e com visualidade? Sem pretensão de respostas, e com uma atitude analítica, fazse um sobrevoo pelo solo que envolve Matemática e Arte para aprender, e assim produzir conhecimento sobre as conexões entre Matemática e Arte que agenciam tipos de aprendizagem. Disso, destaca-se certo ritmo dado a essa temática em Educação Matemática, demarcando uma matriz predominante acerca do aprender Matemática pela Arte. Depois, num descompasso, apresentam-se conexões entre Matemática e Arte, a partir de uma perspectiva crítica da aprendizagem, da visualidade e da metodologia do caminhar, tomando como exemplo pesquisas que apresentam que isso pode ser elaborado por múltiplas maneiras, incluindo relações diversas entre a imagem e a Arte e o visual e a Matemática e os exercícios de pensamentos. Por fim, sem ser modelo, mas obra em processo, coloca-se em estado de travessia com Matemática e Arte e visualidade, em que aprender se torna acontecimento e trans-formação.
\end{abstract}

Palavras-chave: Visualidade. Matemática e Arte. Aprender. Deleuze.

\begin{abstract}
This paper problematizes learning mathematics with art. It starts with questions, such as: How can we not represent mathematics in art, nor instrumentalize mathematical education, but make it a philosophical experience with art and visuality? Without pretending to be able to answer, and with an analytical attitude, there is an overview that involves mathematics and learning through art, and thus produce knowledge about the connections between mathematics and art that tailor these types of learning. From this, a certain rhythm given to this in Mathematics Education stands out, demarcating a predominant matrix about learning mathematics through art. Then, in a mismatch, connections between mathematics and art are presented, from a critical learning perspective, visuality and the methodology of walking, taking as example a set of research works which shows that this can be elaborated in multiple ways, including diverse relationships between image and art and visual and mathematics and thought exercises. Finally, without being a model but a work in process, it is placed in a state of crossing with mathematics and art and visuality, in which learning becomes an event and a trans-formation.
\end{abstract}

Keywords: Visuality. Mathematics and Art. Learning. Deleuze.

\footnotetext{
* Doutora em Educação pela Universidade Federal de Santa Catarina (UFSC). Docente do Departamento de Metodologia de Ensino, Universidade Federal de Santa Catarina (UFSC), Florianópolis, Santa Catarina, Brasil. Email: claudia.flores@ufsc.br.

** Mestra em Educação Científica e Tecnológica pela Universidade Federal de Santa Catarina (UFSC). Doutoranda em Educação Científica e Tecnológica pela Universidade Federal de Santa Catarina (UFSC), Florianópolis, Santa Catarina, Brasil. E-mail: monicakerscher@gmail.com.
} 


\section{Daquilo que se anuncia: à guisa de introdução}

Matemática e Arte e visualidade em experiência na escola diz da perspectiva de trabalhos de pesquisas ${ }^{1}$ que encontram na Arte e no visual a re-invenção de modos de aprender e ensinar Matemática: fazer conexões entre Matemática e Arte, não matematizando a Arte, nem representando a Matemática, mas buscando uma potência nessa articulação, no entre, no exercício do pensamento, das práticas visuais, da própria visualidade. O que significa dizer que não se busca ver Matemática na Arte, tampouco fazer da aula de Matemática um lugar prazeroso, motivado pela Arte, e tampouco aprender Matemática reconhecendo conteúdos matemáticos na obra de Arte. Mas entre as duas, Arte e Matemática, experimentar modos de ver, de pensar e de aprender, em que a Matemática se destaca como elemento organizador que forma um tipo de imagem do pensamento: racional, objetivo, cartesiano.

Ora, daí que o que se pode fazer é forçar o pensamento, provocando-o, inventando problemas e problematizando. Isto pois, para além de se manter na assimilação e acomodação de conceitos, de fórmulas matemáticas, de formas geométricas, por exemplo, provocar o encontro com o mundo dos signos, visto que "o que nos força a pensar é o signo" (DELEUZE, 2006b, p. 91). Da mundanidade (fórmulas, formas matemáticas, etc.) a memória possui um grande efeito, para além disso, então, rasgar fissuras e provocar o encontro com outros mundos. Os signos mundanos não surgem apenas como memórias ou vacuidades informativas, com eles há encontros amorosos e sensíveis por onde alguma coisa acontece, por exemplo, pensar sobre Matemática, conhecer Matemática, pensar sobre aprender e ensinar Matemática com Arte. Assim, experimentar o próprio pensamento, em que: "Pensar não seria um tipo de aprendizagem que acontece experimentando formulações matemáticas, pensamento matemático?” (FLORES, 2017, p. 185).

Aprender não é re-produzir, mas inaugurar; inventar o ainda não existente, e não se contentar em repetir um saber [...]; pois é preciso desfazer os "aparelhos de saber", as organizações preexistentes, incluída a do corpo, para devir, entrar em "devires" que comandam e balizam toda criação (SCHÉRER, 2005, p. 1188, grifos do autor).

É nesse sentido que viemos desenvolvendo nossas pesquisas. No delírio do problematizar uma Matemática que se enviesa pelo e no pensamento, que agencia modos de pensar, falar e estar no mundo, uma Matemática que funciona "como um esquema [ideal] por meio do qual aprendemos [em nossa historicidade] a olhar para as coisas do mundo" (FLORES;

\footnotetext{
${ }^{1}$ Pesquisas desenvolvidas no âmbito do Grupo de Estudos Contemporâneos e Educação Matemática, GECEM (www.gecem.ufsc.br), notadamente aquelas resultantes dos projetos "Traços de criança: pensando matemática por meio de imagens da arte" (FLORES, 2016a) e "Desdramatizar a Educação (Matemática): Experiências com Oficinas de Arte no Ensino Fundamental" (FLORES, 2016b).
} 
MACHADO; WAGNER, 2018, p. 138, grifo das autoras). Esses fragmentos de memórias de Matemática, que estão sempre em nosso encalço, aparecem, assim, como um álibi para pensar sobre Matemática: conhecer Matemática; problematizar a Matemática ensinada na escola; extravasar o dado e aprender Matemática com Arte. Aquilo que atua entre Arte e Matemática força o pensamento, e por esta conexão que se inventam, ou reinventam práticas matemáticas: na fala, na escuta, no tato; no riso e no sorriso, no desenho e na escrita, no som e no silêncio, no cheiro e no olhar; na arte e no estar; na cor e no delírio do verbo.

Portanto, para esse tipo de composição com a Arte e a Matemática, "não tem modelo, é um devir, um processo [...], sua potência provém do que ela soube criar, e que passará mais ou menos para o modelo, sem dele depender" (DELEUZE, 2013, p. 218). Dito isso, como não ceder às tão requisitadas demandas instrumentalizadas para o ensino da Matemática com o uso da Arte? Como não representar a Matemática na Arte, nem instrumentalizar a Educação Matemática, mas fazer disso uma experiência filosófica com Arte e com visualidade? Como aprender Matemática com Arte pelo exercício do pensamento, em que aprender seja um acontecimento?

Sem pretensão de respostas, tais problematizações foram lançadas neste ensaio a fim de caminhar junto com a escrita, fazendo um sobrevoo pelo solo que envolve Matemática e Arte para aprender, e assim produzindo conhecimento sobre as conexões entre Arte e Matemática que produz um certo tipo de aprendizagem. Depois, ensaiar uma atitude analítica em que o aprender ocorra em meio a experiências concretas, pelo encontro de signos, tomando cenários de pesquisas que lidam com oficinas no ensino fundamental, Matemática, Arte e visualidade.

\section{Aprender Matemática pela Arte e aprender Matemática com Arte}

Se a senhora me fala de regressão, eu lhe respondo com reencontros! O saber, é antes de tudo, carnal. São os ouvidos e nossos olhos que o captam, nossa boca que o transmite (PENNAC, 2008, p. 124).

Passemos, então, sobre aprender Matemática pela Arte. De certo modo, percebe-se que, em primeira instância, a composição da Arte para o ensino da Matemática, e o aprender em Matemática com a Arte, se realiza por diferentes enfoques, como indicado no mapa e inventário de pesquisas realizado por Flores e Wagner (2014), no qual foram encontrados vinte e cinco trabalhos brasileiros entre teses e dissertações no período de 1987 a 2013. As autoras buscaram compreender os lugares teóricos que tais pesquisas se apoiavam, mostrando "como a arte é relacionada com a matemática a fim de se proporcionar aprendizagem e entendimentos acerca da construção do conhecimento matemático" (FLORES; WAGNER, 2014, p. 251). Segundo as 
autoras, as pesquisas tendem a se relacionar com a perspectiva da interdisciplinaridade, na relação da arte com Matemática que, em linhas gerais, a obra de arte é tomada como lugar para reconhecer o conhecimento matemático, uma ferramenta de contextualização, aplicação ou identificação de conceitos e saberes, tornando a aprendizagem matemática mais significativa para o estudante.

No rastro disso, e não de modo generalizado da pesquisa sobre Matemática e Arte, investigamos alguns trabalhos indo um pouco mais além do período de tempo cercado por Flores e Wagner (2014). Assim, Barros (2017), por exemplo, numa perspectiva interdisciplinar entre Matemática e Arte, desenvolveu sequências didáticas e discutiu o ensino-aprendizagem de conceitos matemáticos por meio de alguns recursos, dentre eles obras de arte. As sequências didáticas envolviam a habilidade de leitura visual e geométrica, por meio de identificação e definição de conteúdos nas obras de arte, tais como: simetria, polígonos, poliedros, figuras planas e espaciais, formas bi e tridimensionais, ângulos.

Albuquerque (2017) também utilizou a Arte como meio para o ensino de geometria e ferramenta de contextualização do conteúdo. Neste caso a Arte foi colocada como uma possibilidade, entre tantas, de estratégia didática para o ensino de geometria, partindo, inicialmente, da apresentação do conteúdo de geometria plana e espacial, para depois fazer a identificação da geometria presente em pinturas e origamis. Santos (2018) trabalhou na perspectiva da produção de um recurso tecnológico como possibilidade pedagógica. Desenvolveu um aplicativo que auxiliasse os estudantes para que, ao olharem para uma obra de arte, não vissem apenas uma pintura, mas detectassem a Matemática nas formas e lessem a pintura matematicamente.

Feito isso, não há por que avançarmos muito mais. Por ora, inspiradas por esses trabalhos, sustentamos que aprender Matemática pela Arte tem sido baseado, normalmente, pelo reconhecimento de formas geométricas, pela materialização de conceitos abstratos e identificação de conhecimentos diversos da geometria e da Matemática, em que a atividade cognitiva e mental desenvolvem um papel primordial. Com isso, no que tange às questões do visual, a arte tem sido instrumento para o treino de operações mentais, o desenvolvimento de habilidades visuais e para a educação do olhar em Matemática, notadamente a geometria tridimensional. Disso, pois, "aprender tem sido, habitualmente, uma repetição de experiências já realizadas, um contato com as descobertas das ciências, um estudar as regras e postulados" (FLORES, 2016, p. 505).

Tudo isso, entretanto, faz parte de nossa cultura ocidental. Se buscarmos a etimologia da palavra aprender, por exemplo, vemos que ela 
é de origem latina e remonta ao verbo prehendo, 'tomar', 'colher', [...] [e que] pressupõe a ideia de que o conhecimento é algo que se toma e se assimila. [...] De fato, entender o conhecimento como um prehendere não difere em muito da explicação piagetiana do comportamento psicológico do sujeito diante do novo conhecimento como 'assimilação' e 'acomodação' (CASTELLO; MÁRSICO, 2007, p. 120-121, grifos dos autores).

Daí que, o que nos persegue é uma herança platônica, formando uma matriz no pensamento educacional e pedagógico em que aprender baseia-se na recognição, em voltar ao mesmo para relembrar, onde “a alma vai, aos poucos, se 'recordando' daquilo que já sabia. O aprender constitui-se, pois, numa recognição, em voltar a saber algo que já se sabia" (GALLO, 2017, p. 104, grifo do autor). E, ainda que tenham surgido outras elaborações teóricas no campo educacional contemporâneo sobre aprender, sobre aprendizagem, esta matriz continua predominante entre nós.

Instigadas por isso, vimos que "a forma da recognição nunca santificou outra coisa que não o reconhecível e o reconhecido, a forma nunca inspirou outra coisa que não fossem conformidades" (DELEUZE, 2006a, p. 195). Daí, "com efeito, existe um modelo: o da recognição" (DELEUZE, 2006a, p. 193). Neste modelo há uma natureza reta do pensamento e uma boa vontade do pensador. Isso quer dizer que o pensamento se dá de forma natural, é inato, e que ele está predisposto ao conhecimento verdadeiro. Entretanto, para que isso seja possível, isto é, para que o aprendiz alcance o conhecimento é necessário que alguém esteja de posse desse conhecimento e ensine. Como se houvesse um movimento de causa e efeito, de implicação e ligação direta: alguém ensina e o outro aprende, consequentemente. Assim, nesse modelo, só se aprende aquilo que é ensinado, levando-nos, supostamente, a uma homogeneização: todos aprendem as mesmas coisas e da mesma maneira. A aprendizagem é, nesse caso, o resultado da passagem do não-saber ao saber, do local de partida ao ponto de chegada tão esperado.

Podemos considerar que, por isso, se buscam resultados de uma aprendizagem objetiva, com intenção de controle por meio do ensino de habilidades, competências e conhecimentos, que sirva para um ideal predeterminado, que seja desejável e útil para o futuro. Disso, o aprender é modulado e subjetivado pelo que se denomina de sociedade da aprendizagem, por onde se introduz tecnologias e procedimentos para que possamos nos tomar aprendizes por toda a vida (SIMONS; MASSCHELEIN, 2011).

Disso tudo fica que a aprendizagem é focada na representação, assimilação, acomodação e repetição de regras e ordens dadas, e tem sua finalidade nos valores e resultados estabelecidos, preferindo hábitos e costumes do que alguma forma de questionamento, estranhamento ou suspeição. O que dita, então, é a direção natural da percepção ou da 
representação do mesmo, do semelhante, e de uma identidade que evita qualquer multiplicidade: tenta-se enquadrar a diversidade em uma unidade.

Entende-se que a negação da diferença, das multiplicidades, é o propósito do
pensamento dogmático, pois as "perturbações" atrapalham o bom e reto pensamento,
e as forças avessas e estranhas desmobilizam as normas e as regras estabelecidas, tão
caras ao processo educativo, por exemplo (RAMOS; BRITO, 2014, p. 187, grifo das
autoras).

Daí que, aprender Matemática pela Arte tem sido, majoritariamente, voltado ao processo cognitivo, à memorização, ao reconhecimento e à repetição, para a apreensão de conhecimentos matemáticos, assim como para o desenvolvimento de habilidades visuais. Ora, "é evidente que os atos de recognição existem e ocupam grande parte de nossa vida cotidiana: é uma mesa, é uma maçã, é o pedaço de uma cera” (DELEUZE, 2006a, p. 195), bem como na sala de aula de Matemática: é um retângulo, é uma reta, é proporcional. Portanto, os atos de recognição surgem na mundanidade. Daí, os signos mundanos já existentes, e não menos importante, mas seriam por eles que se poderia extravasar e possibilitar o encontro com os signos amorosos e sensíveis, enquanto mundo seguinte do aprendizado. Ressaltamos, todavia, que o aprender não se resume apenas pelos atos recognitivos, pois se entende que eles são somente uma das ocupações do pensamento. Mas, certamente, que por meio deles é que se criam possibilidade de aprender, amando, sentindo, ensaiando e, até, artistando.

Dito isso, e compreendendo que aprender vai além da recognição, seguimos a pensar com Deleuze (2006a, 2006b) sobre aprender Matemática com Arte. Com ele aprendemos que qualquer relação, com pessoas, com coisas, possui o potencial de mobilizar em nós um aprendizado, pois como já dito, aprender é um encontro com signos. "Nunca se aprende fazendo como alguém, mas fazendo com alguém” (DELEUZE, 2006b, p. 21). E "nada aprendemos com aquele que nos diz faça como eu. Nossos únicos mestres são aqueles que nos dizem 'faça comigo' e que, em vez de nos propor gestos a serem reproduzidos, sabem emitir signos a serem desenvolvidos no heterogêneo" (DELEUZE, 2006a, p. 48, grifo do autor).

Por esse viés, o aprender é singular, acontece singularmente com cada um. "Aprender, pois, como acontecimento, como presença espaciotemporal, como processo, como passagem. [...] aprender é da ordem do sensível (encarnar-se) mais do que do inteligível, simplesmente" (GALLO, 2017, p. 111). Tal qual nos sugere Pennac (2008), na epígrafe desta seção: “o saber é, antes de tudo, carnal”.

Aprender Matemática com Arte nos leva, assim, a vislumbrar um tipo de aprender que ocorre no entre: entre signos que afetam o corpo, a mente e o pensamento. Aprender, no caso, torna-se em "considerar uma matéria, um objeto, um ser, como se emitissem signos a serem 
decifrados, traduzidos, interpretados" (DELEUZE, 2006b, p. 4). Com a obra de arte aumentase a potência, possibilitando-se o encontro com o mundo dos signos. $\mathrm{O}$ ato de decifrar signos pode, então, surgir no recortar, colar, colorir, dobrar, olhar, ouvir, e é na contingência desse encontro, do encontro com os signos, pelo inusitado, e não pela representação ou a recognição sempre do mesmo, que se constitui o próprio aprendizado.

Com isso, busca-se um descompasso daquilo que se tem como tendência naturalizada de se tratar a Educação Matemática e a Arte, por assim dizer, pois nos movimentamos por uma postura de suspeitar do que é tido como natural, constituído como regra, além de não nos contentarmos em fazer o mesmo. O que não significa fazer diferente, fazer um novo, mas tirar da natureza as naturalidades e problematizar os conjuntos de verdades, como Foucault nos faz estudar, tendo em vista que os efeitos de verdade produzem um modo de pensar, olhar e representar o mundo, inclusive na sala de aula de Matemática. Assim, enfim, aprendendo Deleuze, recriamos algumas passagens de pesquisas que realizamos, para que, narrando-as, possamos tecer algum sentido e, talvez, desbravar os signos do meio onde o aprender acontece ${ }^{2}$.

\title{
3 Entre Matemática e Arte: conexões descompassadas no aprender
}

\begin{abstract}
Nada de pânico, senhor inspector, é preciso brincar com o saber. A brincadeira é a respiração do esforço, a outra batida do coração, ela não atrapalha a seriedade da aprendizagem, ela faz o contraponto. E, além do mais, brincar com a matéria é ainda uma forma de treino para conhecê-la. Não trate como criança o lutador de boxe que está pulando corda, é imprudente (PENNAC, 2008, p. 130).
\end{abstract}

Avivar uma postura que se encontra no entre requer uma desestabilização dos modos habituais e acostumados de pensar a articulação Matemática e Arte, dito de outro modo, requer colocar-se em escuta e em exercício de pensar e olhar com e para com as visualidades, de certo modo, invisibilizadas, quiçá silenciadas, no ensino e na Educação Matemática. Colocamo-nos, assim, primeiro em espreita: questionando o que é tornado e colocado como natural; olhando com estranheza as coisas no e do mundo; suspeitando do que é constituído como regra; duvidando das certezas; problematizando os efeitos de verdade que produzem um modo de olhar, pensar e representar o mundo e a própria Matemática.

há modos de olhar, de saber, de representar em uma sociedade, que são tão imperiosos a ponto de acharmos que tudo se passa na maior naturalidade, neutralidade. Então,

\footnotetext{
${ }^{2}$ Fazer isso significa, de certo modo, percorrer uma análise filosófica de processos de repetição e re-invenção do pensamento, em que aprender Matemática com a Arte se processa de um lado como efeito de colonialidade do saber e, de outro, como forma potente de um falar próprio dos estudantes, conforme objetivo do Projeto de Pesquisa intitulado "Formas e De-formas no Olhar: Por uma Educação Matemática Fronteiriça e Criadora" (FLORES, 2019).
} 
não questioná-los é permitir a influência autoritária, é abrir mão da compreensão da historicidade de nosso modo de olhar, de representar, de saber e, ignorantes, se deixar manipular (FLORES, 2007, p. 176).

Dito isso, depois, lançamo-nos em convite: para provocar o pensamento como prática de um modo de aprender; para abrir espaços para os encontros e acontecimentos no percurso educacional; para experimentar modos de ver, com a Arte, em que a Matemática opera como elemento organizador, num processo de conectar-se e desconectar-se, produzindo novas possibilidades; para considerar a Arte na sua potência de forçar a pensar, e assim, aprender com, no entre Matemática e Arte. E, assim, render-se ao convite: encontrar-se com os signos, com certa disposição para perder tempo, reinventando-se na experiência e no pensar, no tempo perdido oportunizar a possibilidade de aprender e, enfim, redescobrir o tempo redescoberto, a aprendizagem, pois que “quando pensávamos perder tempo, já fazíamos o aprendizado dos signos" (DELEUZE, 2006b, p. 23).

Transitar pelo meio (que não é uma média, ao contrário, é lugar onde as coisas adquirem velocidade e intensidade, e que, ao mesmo tempo, perdem o passo acostumado e ganham outro caminhar, no entre, na travessia, em processo) é per-correr pelo meio do riacho, como sinalizado por Deleuze e Guattari (1995). Dito de outro modo, é fazer um descaminho, como apontado por Flores (2016), descompassando a precisão do deslocamento de um modo de pensar colonizado, representativo, isto é, de um pensamento natural e cristalizado para se olhar as obras, as imagens da arte, e ver Matemática, representar conhecimentos e conceitos, ou repetir as intenções do artista, matematizando a Arte e reconhecendo a Matemática, ou mesmo fazendo da aula de Matemática uma representação artística, motivacional, experimental. Daí que se produzem movimentos que desterritorializam e tiram do ritmo costumeiro o nosso pensar a Educação, a aula de Matemática, o aprender pela/com a Arte e, até mesmo questionando sobre o que faz a Arte com o aprender Matemática.

Assim, caminha-se nas veredas de uma possível articulação entre Arte e Educação Matemática que vai além das habituais, ofuscando a matriz hegemônica e naturalizada de se conceber a Matemática, o ensino e a aprendizagem, e percebendo que tudo isso pode ser elaborado por múltiplas maneiras, incluindo relações diversas entre imagem, arte, visual e Matemática.

Daí que se considera um tipo de exercício que vem sendo denominado por nós de "oficinas" - oficinas dispositivos, oficináticas, oficina-experiência -, que remete, de um lado, ao estudo de imagens da Arte que potencializam a Matemática como forma de pensamento, em sua mundanidade e, de outro, à experiência fazendo elaborações matemáticas que levam a 
compreender a intenção, a formulação e o efeito das imagens da arte. As oficinas, com uma função de provocar visualidades, saberes e experiências, mostram formas de olhar, conceber e desenhar, em que a naturalização da Matemática na representação das coisas no mundo, incluindo a Arte, se abre à crítica e à denúncia de formas hegemônicas, mas também à forma criativa do pensamento, abrindo-se à multiplicidade, à heterogeneidade, à invenção de novas possibilidades, visto que o aprender é o avesso da reprodução do mesmo.

Disso, fazemos pesquisas como formas de ensaios sobre o aprender Matemática com Arte. O que só pode ser realizado por um movimento em processo, nômade, num ato mesmo de caminhar, de parar, de olhar, de dar atenção, de perder tempo, de abrir-se aos encontros e forçar o pensar.

\subsection{De uma Martemática com crianças}

Como gaguejos soam quando se fala de aprender Matemática com a Arte, pensando numa matemática-entre-arte, em pesquisas que operam por problematizações e no deslocamento teórico-conceitual da visualização-visualidade?

O ritmo se transforma, pois não se procura tão somente em desvendar geometrias da Matemática na Arte ou através da Arte, pela Arte. A Matemática não surge como objeto empírico ou transcendente que compõe ou representa uma imagem na pintura (FLORES; MACHADO; WAGNER, 2018), mas que, com a Arte, criam-se problematizações acerca de um pensamento matemático - de uma imagem do pensamento (DELEUZE, 2006a) - que se entremeia no ver, no saber e no aprender Matemática. Problematiza-se a conjunção de discursos que formam e informam como vemos, estranhando as formas naturalizadas de olhar e representar as coisas no mundo, e assim "as certezas se desfazem e algo se pode criar no pensamento e na vida" (BARROS; ZAMBONI, 2012, p. 123), na Matemática. Portanto, podemos dizer que soa um modo outro, des-ritmado, de re-invenção para tomar tal relação, qual seja, da Matemática com a Arte na Educação Matemática a partir da perspectiva da visualidade (FLORES, 2013). Ora, quanto de inusitado guarda e ressoa de uma experiência com a visualidade, as pinturas e a matemática?

\footnotetext{
- Olha que incrível, em espanhol doze é 'doce'. Eu adoro doce e doze. Esse número é um número especial!

Inaugura-se um sentido para o doze. As crianças buscam sentidos, estabelecem relações. Uma relação de diferença com o mundo. Enquanto isso, "estamos sempre dependurados sobre o muro das significações dominantes" (KERSCHER, 2018, p. 112).
}

Numa sala de aula de Matemática de quinto ano dos Anos Iniciais do Ensino 
Fundamental balbuciou-se com o doze, pensou-se com ele, fez-se dele um sentido. Gaguejouse - visto que "gaguejar é quando as palavras perdem seu sentido estabelecido. Quando o que é o fora dos pensamentos, das ideias já estabelecidas, nos invade e nos causa vertigem, gagueira" (BARROS; ZAMBONI, 2012, p. 122). Daí vem o ciúme: o signo amoroso não se deixa mostrar, ele traz consigo formas que nem sequer podíamos imaginar, que não nos pertencem, ele é ilusório, mas nos afeta, nos instiga, e nos leva a buscar.

Foi nesse espaço de vertigem e de abrir possibilidades para um aprender Matemática com Arte que uma martemática foi forjada, pela gagueira, na pesquisa desenvolvida por Mônica Kerscher (2018), intitulada "Uma martemática que per-corre com crianças em uma experimentação abstrata num espaço-escola-espaço”. Nela abriu-se espaço e tempo para pensar com os gaguejos de uma Educação Matemática num entrecruzamento com a experiência, com as formas de olhar, com arte abstrata geométrica, com Matemática, com crianças, por meio de oficinas.

$\mathrm{Na}$ pesquisa acima mencionada com as oficinas ${ }^{3}$ não se objetivava pensar e elaborar estratégias metodológicas para colher dados para a pesquisa. Tampouco elas funcionavam como motivação para representar conceitos, pois o que menos importava ali era o conceito em si, a não ser ele como potência no mundo dos signos da mundanidade e aquilo que ele permitia pensar, fazer transitar por possibilidades do próprio pensamento, do novo com a novidade, e que também está no velho. E, na trans-formação daquilo que se vê e se ouve, de si mesmo, pensando o que se vê e não vendo o que se pensa, permitir pensar de novo e novamente, incitando a experiência na travessia de visualidades compostas de martemáticas (KERSCHER, 2018).

E então o que acontece quando um grupo de quatro ou cinco crianças se depara, na oficina "colorritmos", por exemplo, com diversas caixinhas de dois tamanhos distintos, colocadas dentro de uma caixa maior, e com a tarefa de fazer a divisão delas para cada criança - sem a imposição de quantidade e sem orientações pré-estabelecidas? Isto é, sem a determinação do como fazer, mas no encontro com algo? Seria isso tipo fração sem estabelecer fração? "Em primeiro lugar, é preciso sentir o efeito violento de um signo, e que o pensamento seja como forçado a procurar o sentido do signo" (DELEUZE, 2006b, p. 22). Logo, um aprender

\footnotetext{
${ }^{3} \mathrm{Na}$ pesquisa foram desenvolvidas quatro oficinas com três turmas de quinto ano dos Anos Iniciais do Ensino Fundamental do Colégio de Aplicação UFSC, no período de março e abril de 2017. As oficinas foram intituladas de "Ex-pectador-autor", "Cores em forma", "Colorritimos" e "A obra toca o corpo, o corpo mexe a obra", com inspiração na Coleção Patrícia Phelps de Cisneros de obras de arte de artistas latino-americanos como Lygia Clark, Hélio Oiticica, Carlos Cruz-Diez, Alejandro Otero, entre outros. Tais obras (pinturas, esculturas e instalações) envolvem, de modo específico, a arte abstrata geométrica.
} 
com "os restos de uma matemática que se coloca como modo de pensar e estar [no mundo]. Um modo de pensar que confronta ideias, argumentos, tomadas de decisões, estabelecidas por situações, modelando um modo de pensar a matemática" (KERSCHER; FLORES, 2019, p. 15, grifo das autoras). No encontro com as caixinhas uma brecha para criar e improvisar em (Educação) Matemática, para pensar com elas e não reconhecer, identificar algo, ou reproduzir e copiar, mas sobretudo pensar, pois, como Deleuze sugere, quando se pensa, se aprende.

Algumas crianças, no meio das oficinas, insistiam em saber se aquilo que estava sendo invencionado tinha a ver com a Matemática; em saber qual o início, meio e fim. Uma vontade de saber e de antecipar o resultado do que, possivelmente, se obteria com todas aquelas cores, formas e texturas na oficina "cores em forma"; e com caixinhas, pedrinhas e tampinhas na oficina "colorritmos"; e com a produção de uma forma geométrica com a sua cor favorita, ou o porquê de cortar uma fita de Möbius colorida circulando a extensão da tira de papel sem dividila em duas na oficina "ex-pectador-autor" ou, ainda, o que seria feito com caixinhas sobrepostas e cheias de materiais, por exemplo. Elas esperavam os significados, as utilidades, os motivos, para colocar na ordem do que elas estavam acostumadas, isto é, para dar um sentido àquela possível aprendizagem, àquele signo mundano que as interpelava. Queriam saber de antemão qual seria o aprendizado do dia, como se pudéssemos controlar e dizer o que se vai aprender, o que se aprende e como se aprende. "O tempo que se perde prolonga-se no amor e mesmo nos signos sensíveis; o tempo perdido já aparece na mundanidade e subsiste ainda nos signos da sensibilidade" (DELEUZE, 2006b, p. 23).

Diferentemente do costumeiro, tudo se movimentava no fluxo e na intensidade em não transformar aquilo que se fazia em reprodução e representação, ou ainda em não fazer da oficina um local de aprendizagem recognitiva sobre algo, ou uma atividade de repetição de fazer como alguém fez, de praticar pela identificação dos saberes já consolidados ou, então de não fazer com que cada atividade fosse uma utilidade imediata para um possível futuro. Aos poucos, essas vontades e essas "relações utilitaristas são separadas destas atividades, porque nesses momentos o que está em jogo, em ato, é uma produção, um pensamento” (FLORES, 2017, p. 185).

E então, pensando assim, algo acontece, "alguma coisa acontece", e essa "coisa" não é dada pela recognição, tampouco pelas faculdades divergentes do intelecto. Com a arte, na sua potência de atormentar, provocar, interrogar, o pensamento é forçado e, então, encontros acontecem e o aprender Matemática se faz no exercício do pensar com Arte. Daí que se formula Matemática, abstrações, cálculos, medidas; se pensa o que faz o pensamento matemático e se pergunta como poderia ser de outro modo. Ora, tudo isso avivando um mundo de possibilidades com Matemática e Arte que, pela reação do mundo dos signos, o aprender acontece, artistando. 


\subsection{De traços surreais a mundos (im)possíveis}

Produzir mundos no mundo e levantar voos no pensamento, deixando que a imaginação flua e crie múltiplas possibilidades de ver e dizer no mundo. A criança é "dona" do mundo e seu mundo pode ser qualquer mundo - real ou sonhado, visível ou invisível, ela o cria e o recria. Nesse meio, o que acontece quando crianças se deparam com a proposta de colagem com recortes de revista em uma superfície não-euclidiana, por exemplo, a superfície ondulada da caixa de ovo, permitindo o movimento de se opor a qualquer padrão estético ou racional? "Colar aqui? Que estranho!”, exclamou uma criança. “O estranhamento provoca o pensamento: a arte surrealista gera inquietação, e essa inquietação gera pensamentos" (SOUZA, 2018, p. 46), que podem ser pensamentos matemáticos, ou não. Mas, signos que se acionam por onde a expressão de estudantes refletem mundos próprios e manifestam suas formas de aprender Matemática, misturadas com seus modos de ser, de olhar e de pensar.

$\mathrm{Na}$ oficina realizada por Jéssica Souza $(2018)^{4}$, com crianças e Arte surrealista e Matemática, movimentou-se uma vontade de potência de conhecer mundos, no mundo. A oficina "buscava explorar um mundo novo: sem forma, sem razão, sem lógica - ou sem o que convencionamos a chamar de forma, razão e lógica" (SOUZA, 2018, p. 41). Ela transitava pela composição de um mundo imaginado pela criança, o próprio mundo onde tudo é possível, um mundo que não representa o mundo visível, quiçá distante da recognição. Tudo isso numa tentativa de desterritorialização da ordem e do padrão estabelecido de ver e habitar o mundo visível.

Assim, de um possível encontro com signos entre as (des)formas do Surrealismo e a criação de um mundo numa superfície de caixa de ovo, a oficina suscitou questões, levantou problemas e, principalmente, criou condições de possibilidades de pensar com Arte e Matemática:

Qual o estranhamento causado pelo contato com um mundo que não representa o real? Como lidar com uma geometria outra? Como ficam as figuras coladas em uma superfície não-euclidiana? Sofrem alguma alteração? Ficam estranhas? São reais? (SOUZA, 2018, p. 59).

Em vez de representá-lo, um mundo foi apresentado, ou mais que isso. Num movimento de repetir para diferenciar deu-se a ouvir uma apresentação de um mundo que buscava confundir e perturbar, um mundo que existia apenas no pensamento e que fez pensar. Um

\footnotetext{
${ }^{4}$ A pesquisa da autora no âmbito de Iniciação Científica, intitulada "Traços surreais no encontro com Salvador Dalí e crianças e matemática e oficina", criou e desenvolveu, com crianças do quinto ano do Ensino Fundamental do Colégio de Aplicação da UFSC, uma oficina envolvendo a arte surrealista do artista Salvador Dalí, impulsionando uma discussão sobre uma geometria não-euclidiana ligada às questões de quadridimensionalidade.
} 
mundo que parecia errado e irreal, portanto, surreal. As crianças envolvem-se com esse mundo, concreto, e deixam suas marcas, deixam suas digitais, deixam linhas, pontilhados, cores, tudo com sua própria arte, com suas próprias mãos. Os mundos criados na superfície de caixas de ovos são obras de suas medições, de seus recortes, de suas dobraduras, de suas colagens. Nesse meio, há algo que escapa do conteúdo, do dado, do conhecimento necessário para compor uma representação numa superfície totalmente estranha aos ensinamentos matemáticos. Aqui há uma brecha? Sim. E por ela se fez pensar e aprender. Fez pensar na relação do real com as coisas, uma vez que, pelas falas das crianças, na oficina pôs-se vidência, luz, em certos entrelaçamentos entre o real e a Matemática:

\footnotetext{
- O real tem a ver com proporção: algo grande demais ou pequeno demais não faz parte do mundo real; necessita de uma função ou nome diferente para que faça parte de algum mundo inventado.

- O real tem a ver com a forma: e a forma tem a ver com a beleza. É belo e real o que mantem [sic] sua forma original, sem deformações. Figuras deformadas e retorcidas são estranhas, loucas e feias.

- O real tem a ver com organização e método: as coisas parecem ser mais reais quando estão organizadas e categorizadas. Imagens embaralhadas e misturadas deixam o mundo confuso e estranho.

- O real tem a ver com a razão: e a razão tem a ver com o correto. $\mathrm{O}$ que foge à nossa razão e ao nosso sentido causa estranhamento e é associado a algo errado, que precisa ser corrigido, feito de outra forma ou desfeito.

- O real tem a ver com um modelo: o real é a representação do que vemos, reprodução do mundo tal como ele se apresenta a nós. Qualquer coisa que não reconheçamos foge da realidade.

- O real tem a ver com a geometria euclidiana: para representar o real, é indicado o uso de uma superfície plana, que não acarrete em perturbações nas imagens. Objetos representados em outra geometria não são parte da realidade (SOUZA, 2018, p. 62, grifos da autora).
}

Exercícios de pensamento para pensar e fazer pensar, para estranhar: "a colagem em caixas de ovos tinha mesmo a intenção de causar estranhamento, o professor faz existir algo novo - e portanto estranho" (SOUZA; FLORES; MACHADO, 2020 p. 6). Ele apresenta a matéria e as mundanidades surgem rapidamente. Ele apresenta o mundo para que algo aconteça. Ele abre mundos dos signos: o mundo dos signos amorosos, dos signos sensíveis e, assim, convida ao encontro com eles. Daí que o aprender acontece, não somente pela transmissão de um conteúdo que deverá ser assimilado pelos estudantes, mas que se consolida entre os mundos possíveis, possibilitando revelar um mundo artístico que reage sobre todos, professor e estudantes.

O estranhamento fez pensar de outra maneira, para ver o mundo - desnaturalizando-o. Ver o mundo de outra maneira, atentar-se ao mundo. Atentar-se de outra maneira, brincar com ele. Sem imposição de sentidos e significações, sem a prescrição de modos de como fazer. Mas sim abrindo espaço para fazer com, estar com e experienciar o encontro, os acontecimentos e os pensamentos, criando no pensamento o ato de pensar, pois o aprender se faz também pelo 
exercício de pensar e "pensar é fazer pensar" (DELEUZE, 2006b, p. 105). E, então, compondo com a passagem de Pennac, epígrafe desta seção: nada de pânico, senhor professor, para aprender é preciso brincar com o saber.

\title{
4 Minuta em obra: a intermitência de um ponto de interrogação
}

\author{
Porque não existe nenhum outro objetivo da correção de \\ um ditado além do acesso ao sentido exato do texto, \\ ao espírito da gramática, à amplitude das palavras. \\ Se a nota deve medir alguma coisa, \\ é a distância percorrida pelo interessado \\ no caminho dessa compreensão (PENNAC, 2008, p. 113).
}

Afinal, o que se aprende em Matemática pela Arte? Alguns vão responder dizendo que explorar a reprodução ou representação de conceitos, saberes e conhecimentos matemáticos pela Arte, em sua mundanidade apenas, assegurará a aprendizagem no ensino de Matemática, uma vez que há a reunião "da teoria e da práxis", em termos de aplicação do que foi ensinado. Ao abraçar essa ideia toma-se como premissa que o ensinar tem a ver com o explicar e o aprender tem a ver com reconhecer e reproduzir o ensinado, numa relação direta entre ensino e aprendizagem, ligando indissociavelmente o ensinar e o aprender.

E o que se aprende em Matemática com Arte? Distanciando-nos da resposta inicial habitualmente dada e, possivelmente, encontrada na literatura, e sem pretensão de esgotar ou mesmo responder tal questão, mas inspiradas em Deleuze, sustentamos que não há como afirmar ou como prever o que se aprende, não há como anunciar efetivamente o que se aprende sobre Matemática na sua relação com a Arte. Porque aprender é exercício de pensamento, é encontro com signos, é processo, é acontecimento. Aprender é fazer com, é sempre encontrarse com o outro, com alguma coisa, com a diferença. Aprender é movimento na sensibilidade, no corpo, é encarnar-se. Tudo isso, portanto, é algo que não pode ser antecipado, nem calculado ou medido. E, assim, mais uma vez, relembrando Pennac (2008, p. 113), citado na epígrafe desta seção, "se a nota deve medir alguma coisa, é a distância percorrida pelo interessado no caminho dessa compreensão".

Se o aprender segue a via dos encontros, então ele deixa de ser aquisição; e ensinar não corresponde, obrigatoriamente, ao aprender. A aprendizagem está do lado do rato no labirinto, e não fora da caverna ao considerar somente o resultado - o saber - para dele extrair os princípios transcendentais (DELEUZE, 2006a). A aprendizagem escapa a qualquer controle. E mais, "a aprendizagem não se faz na relação da representação com a ação (como reprodução do Mesmo), mas na relação do signo com a resposta (como encontro com o Outro)" (DELEUZE, 2006a, p. 
54).

Entendido assim, a pergunta inicial perde seu sentido e se transforma em sua intermitência: que encontros acontecem quando se atrita Matemática com Arte? Pois bem, o que se pretende, antes, é ressoar os planos de composições da Arte e de imanência da Matemática para que algo aconteça desse encontro, deste atrito: aprender Matemática com Arte, em condições artísticas.

Ao exercitar um "pensamento sem imagem"5 quiçá possamos pensar a Educação Matemática

no âmbito da crítica, da denúncia de um estado de coisas perpetuado pela modernidade, $[\ldots]$ e no convite a uma construção coletiva de elementos que possam conectar-se e reconectar-se, produzindo novos panoramas, novas possibilidades. A educação pensada, vivida e praticada como devir e abertura (GALLO, 2018, p. 804).

Dito isso, a minuta que se esboça, sem ser modelo, mas obra em processo, é a de uma possibilidade de abrir-se em travessia pelos mundos dos signos, com Matemática e Arte e visualidade em experiência na escola. Daí que se ensaia que se aprender é acontecimento no pensamento, num sentido de passagem, processo, então aprender está na ordem da transformação: aprender alguma coisa é aprender com ela; o que não quer dizer sabê-la. $O$ aprendizado, tomado como experimentação aleatória, exercita a interpretação de signos, na medida em que um signo é colocado como problema para o pensamento.

\section{Agradecimentos}

Agradecemos e ao CNPq pela bolsa produtividade e a Capes-Proex pela bolsa de doutorado, oportunizando o desenvolvimento deste trabalho.

\section{Referências}

ALBUQUERQUE, E. S. C. Geometria e arte: uma proposta metodológica para o ensino de geometria no sexto ano. 2017. Dissertação (Mestrado em Matemática) - Universidade Federal de Alagoas, Maceió, 2017.

BARROS, M.; ZAMBONI, J. Gaguejar. In: FONSECA, T.; NASCIMENTO, M.; MARASCHIN, C. (org.). Pesquisar na diferença: um abecedário. Porto Alegre: Sulina, 2012. p. 119-122.

BARROS, P. B. Z. A arte na matemática: contribuições para o ensino de geometria. 2017. Dissertação (Mestrado em Docência para a Educação Básica) - Universidade Estadual Paulista Júlio Mesquita Filho,

\footnotetext{
${ }^{5}$ Deleuze, no capítulo 3 de Diferença e repetição, esboça que a imagem do pensamento faz com que pensemos apenas dentro dos modelos definidos de antemão, estabelecendo o que se pode pensar e como pensar, o pensamento já pensado, imagem moral e dogmática do pensamento; um pensamento orientado para buscar as verdades universais e atemporais. No entanto, para que o exercício de pensamento seja engendrado como um ato de criação, de acontecimento, Deleuze afirma que é necessário agenciar um "pensamento sem imagem".
} 
Bauru, 2017.

CASTELLO, L. A.; MÁRSICO, C. T. Oculto nas palavras: Dicionário etimológico para ensinar e aprender. Belo Horizonte: Autêntica, 2007.

DELEUZE, G. Diferença e repetição. 2. ed. Tradução de Roberto Machado e Luiz Orlandi. Rio de Janeiro: Graal, 2006a.

DELEUZE, G. Proust e os signos. 2. ed. Tradução Antonio Piquet e Roberto Machado. Rio de Janeiro: Forense Universitária, 2006b.

DELEUZE, G. Conversações. Tradução Peter Pál Pelbart. São Paulo: Editora 34, 2013.

DELEUZE, G.; GUATTARI, F. Mil platôs: capitalismo e esquizofrenia. Tradução Aurélio Guerra Neto e Célia Pinto Costa. Rio de Janeiro: Editora 34, 1995.

FLORES, C. R. Olhar, saber e representar: sobre a representação em perspectiva. São Paulo: Editora Musa, 2007.

FLORES, C. R. Visualidade e Visualização Matemática: Novas Fronteiras para a Educação Matemática. In: FLORES, Cláudia. R.; CASSIANI, Suzani. (org.). Tendências contemporâneas nas pesquisas em Educação Matemática e Científica: sobre linguagens e práticas culturais. Campinas: Mercado de Letras, 2013. p. 91-104.

FLORES, C. R. Descaminhos: potencialidades da arte com a educação matemática. Bolema, Rio Claro, v. 30, n. 55, p. 502-514, 2016.

FLORES, C. R. Traços de criança: pensando matemática por meio de imagens da arte. Projeto de Pesquisa - Edital Universal CNPq 01/2016. Publicação restrita, 2016a.

FLORES, C. R. Desdramatizar a Educação (Matemática): Experiências com Oficinas de Arte no Ensino Fundamental. Projeto de Pesquisa Produtividade - Edital CNPq 12/2016. Publicação restrita, 2016b.

FLORES, C. R. In-fante e Profanação do Dispositivo da Educação Matemática. Perspectivas da Educação Matemática, INMA/UFMS, v. 10, n. 22, p. 171-188, 2017.

FLORES, C. R. Formas e De-formas no Olhar: Por uma Educação Matemática Fronteiriça e Criadora. Projeto de Pesquisa Produtividade - Edital CNPq 06/2019. Publicação restrita, 2019.

FLORES, C. R.; MACHADO, R. B.; WAGNER, D. R. GECEM em montagem ou produzir conhecimento com um grupo que estuda educação matemática. In: CUSTÓDIO, J. F. et al. (org.). Programa de Pós-Graduação em Educação Científica e Tecnológica (PPGECT): contribuições para pesquisa e ensino. São Paulo: Editora Livraria da Física, 2018. p. 129-146.

FLORES, C. R.; WAGNER, D. R. Um mapa e um inventário da pesquisa brasileira sobre arte e educação matemática. Educação Matemática Pesquisa, São Paulo, v.16, n.1, p. 243-258, 2014.

GALLO, S. O aprender em múltiplas dimensões. Perspectivas da Educação Matemática, INMA/UFMS, v. 10, n. 22, p. 103-114, 2017.

GALLO, S. René Schérer e a Filosofia da Educação: primeiras aproximações. Educação e Filosofia, Uberlândia, v. 32, n. 65, p. 793-815, 2018.

KERSCHER, M. M. Uma martemática que per-corre com crianças em uma experiência abstrata 
num espaço-escola-espaço. 2018. Dissertação (Mestrado em Educação Científica e Tecnológica) Universidade Federal de Santa Catarina, Florianópolis, 2018.

KERSCHER, M. M.; FLORES, C. R. Ecos Abstratos)))) Experiências sensibilizadas com matemática e com arte. Revemat: Revista Eletrônica de Educação Matemática, v. 15, n. 1, p. 1-18, 2019.

PENNAC, D. Diário de Escola. Rio de Janeiro: Rocco, 2008.

RAMOS, M. N.; BRITO, M. R. Do pensamento dogmático ao pensamento-problema: por uma aprendizagem-acontecimento. Comunicações, Piracicaba, v. 21, n. 2, p. 183-198, 2014.

SANTOS, E. J. Ensino de perspectiva a partir do olhar matemático: um estudo de caso baseado na Igreja de São Francisco em Ouro Preto. 2018. Dissertação (Mestrado em Educação Matemática) Universidade Federal de Juiz de Fora, Juiz de Fora, 2018.

SCHÉRER, R. Aprender com Deleuze. Educação e Sociedade, Campinas, v. 26, n. 93, p. 1183-1194, 2005.

SIMONS, M.; MASSCHELEIN, J. Sociedade da aprendizagem e governamentalidade: uma introdução. Currículo sem fronteiras, v. 11, n. 1, p. 121-136, 2011.

SOUZA, J. L. Traços surreais no encontro com Salvador Dalí e crianças e matemática e oficina. 2018. Trabalho de Conclusão de Curso (Matemática Licenciatura) - Universidade Federal de Santa Catarina, Florianópolis, 2018.

SOUZA, J. L.; FLORES, C. R.; MACHADO, R. B. Entre palavras e imagens de um mundo surreal: pensamentos matemáticos em uma experiência com crianças e Salvador Dalí. Perspectiva, Florianópolis, v. 38, p. 1-13, jan./mar. 2020. 